\title{
“QUANDO EU ESTUDAVA NO URUGUAI...”: A ESCOLA RECORDADA POR ESTUDANTES DE UM GRUPO ESCOLAR EM PORTO ALEGRE/RS (1948 - 1954)
}

\author{
Alice Rigoni Jacques \\ PPGE/PUCRS \\ alice_rigoni@hotmail.com \\ Dóris Bittencourt Almeida \\ PPGEDU/PUCRS \\ almeida.doris@gmail.com \\ Lucas Costa Grimaldi \\ PPGEDU/PUCRS \\ lucascgrimaldi@gmail.com
}

\begin{abstract}
RESUMO
O artigo investiga memórias de um Grupo Escolar, por meio das narrativas de estudantes, que, entre os anos 1948-1954, frequentaram a instituição de ensino. A escola localizava-se em uma região periférica de Porto Alegre/RS, ainda mantinha traços rurais, sendo também ocupada pela população negra da cidade. Inscrita no campo da História da Educação, valendo-se da metodologia da História Oral, a pesquisa lança olhares à cultura escolar pretérita, tendo como documentos privilegiados as representações das liturgias e práticas escolares, rememoradas por cinco sujeitos. Essas memórias indicam a existência de uma escola adaptada em um antigo casarão, impregnada de conceitos próprios de uma época de consolidação dos grupos escolares, como instituições públicas de ensino.
\end{abstract}

Palavras-chave: História oral. Grupo escolar. Memórias discentes.

\section{"WHEN I WAS STUDYING IN URUGUAY...": THE SCHOOL REMEMBERED BY STUDENTS OF A SCHOOL IN PORTO ALEGRE/RS (1948-1954)}

\begin{abstract}
The article investigates memories of a school group, through the stories of students who, in the years 1948-1954, attended the school. The school was located in a peripheral region of Porto Alegre/RS, still kept traces, is also occupied by the black population of the city. Entered in the field of history of education, using the methodology of Oral history, research school culture looks past launches, with privileged documents renditions of liturgies and school practices, recalled for five subject. Those memories indicate the existence of a school adapted in an old House, full of concepts of a time of consolidation of school groups, like public education institutions.
\end{abstract}

Keywords: Oral history. School group. Students memories.

\footnotetext{
"CUANDO ESTUDIA EN URUGUAY...": LA ESCUELA RECORDADA POR ESTUDIANTES DE UN GRUPO ESCOLAR EN PORTO ALEGRE / RS (1948 - 1954)
}

\section{RESUMEN}


El presente artículo investiga memorias de un Grupo Escolar por medio de las narrativas de estudiantes, entre los años 1948-1954, enlaciudad de Porto Alegre / RS, en una región periférica, aúncon rasgos rurales, también ocupada por lapoblación negra. La investigación se inserta em la Historia de laEducación, arroja miradas a la cultura escolar, a partir de las rememoraciones de cinco sujetos por medio de entrevistas producidas por la metodología de la historia oral en que pudieron reelaborar el tiempo vivido en aquele spacio. Se apreciaron sus representaciones acerca de los meandros de las liturgias y prácticas escolares vivenciadas. Estas memorias indican la existencia de una escuela adaptada em um antiguo caserón, impregnado de conceptos propios de una época de consolidación de los grupos escolares, como instituciones públicas de enseñanza.

Palabras clave: Historia oral. Grupo escolar. Memorias discentes.

\section{“QUAND J'ÉTAIS ÉTUDIANT EN URUGUAY...”: SOUVENAIT DE L'ÉCOLE PAR LES ÉLÈVES D’UNE ÉCOLE À PORTO ALEGRE/RS (1948-1954) \\ RÉSUMÉ}

L'article étudie les souvenirs d'un group escolaire, à travers les histoires des élèves qui, dans les années 1948-1954, a fréquenté l'école. L'école était située dans une région périphérique de Porto Alegre/RS, toujours gardé des traces, est également occupé par la population noire de laville. Entré dans le champ de l'histoire de l'éducation, à l'aide de la méthodologie de l'histoire orale, culture de l'école de recherches emblepassé lance, avec des formats de documents privilégiés des liturgies et des pratiques scolaires, rememoradas pour cinq objet. Ces souvenirs indiquent l'existence d'une école adaptée dans une vieille maison, des concepts d'un temps de consolidation des groupes scolaires, comme les établissements d'enseignement public.

Mots clés: Histoire orale. Group escolaire. Mémoires des étudiants.

\section{UM GRUPO ESCOLAR REMEMORADO POR SEUS ESTUDANTES}

A casa da escola inda é a mesma. Quanta saudade quando passo ali!

Rua Direita, $\mathrm{n}^{\circ} 13$.

Porta da rua pesada,

Escorada com a mesma pedra da nossa infância.

Porta do meio, sempre fechada.

Corredor de lajes [...]

À direita - sala de aulas.

Janelas de rótulas

Mesorra escura

Toda manchada de tinta das escritas.

Altos na parede, dois retratos:

Deodoro, Floriano.

(CORALINA, 1985, p. 75-77).

"Pessoas e escolas têm memórias assentes na tradição oral” (MAGALHÃES, 1999, p. 69). Petronilha, Neusa, Luiza, João Tadeu e Aldo, quando crianças, todos os dias do ano letivo percorriam a Rua Esperança, e dirigiam-se ao número 187, um casarão cercado de jardins. Neste 
lugar, adaptado para o funcionamento de um Grupo Escolar (G.E), eram estudantes do Curso Primário, entre os anos de 1948 a 1954. Hoje, contam com mais de setenta anos, e em suas memórias ecoam fortes lembranças daquela instituição educativa.

Este estudo se propõe a investigar memórias de uma escola de outrora, tendo como corpus empírico narrativas de três mulheres e de dois homens, antigos alunos do Grupo Escolar Uruguai. $\mathrm{O}$ interesse da pesquisa reside naquilo que foi escolhido para ser lembrado, conforme o que diz Éclea Bosi (1979). "O esforço em ouvir o outro para uma ciência mais humana" (SARMENTO, 2003, p. 146) foi o condutor que permitiu a produção de uma inteligibilidade acerca das memórias que emergiram nas entrevistas.

E qual foi o ponto de partida da pesquisa? Um texto autobiográfico (SILVA; PEREIRA, 2011) em que Petronilha e Neusa escrevem memórias do Grupo Escolar Uruguai. Diante desses vestígios, percebemos o potencial desta temática e, assim, fomos em busca de outras percepções acerca daquele lugar, apostando que encontraríamos colegas delas dispostos a serem entrevistados. Localizamos Luiza que indicou os contatos de João Tadeu e Aldo.

Foi assim que se desenvolveram cinco entrevistas, duas delas em duplas, em que as memórias de um evocaram as lembranças de outro. Destacamos a legitimidade de conhecer versões do passado pela oralidade. Como diz Portelli (2016, p. 10), “fontes orais são geradas em uma troca dialógica, a entrevista: literalmente uma troca de olhares". É dessa forma que o autor define a História Oral como uma "arte da escuta", na qual estão implicadas as complexas relações entre entrevistador e entrevistado, em que é preciso ter em vista que vivemos em um tempo e as evocações pertencem a outra temporalidade. Portanto, o trabalho com a História Oral exige conhecimento de quem se propõe a fazê-lo. Somando-se a isso, cumplicidade, escuta sensível e respeito à fala do outro. Errante (2000) endossa a importância dessa metodologia no campo da História da Educação, afirma que "as histórias orais acrescentam uma dimensão nãooficial inestimável” (2000, p. 146) às investigações educacionais, justamente por viabilizarem narrativas de sujeitos envolvidos na pesquisa. Deste modo, colocam-se em evidência documentos orais, que, muitas vezes, traduzem, de modo singular, as experiências vividas no contexto escolar.

Considerando que aquele que narra, o faz a partir dos lugares ocupados no passado e no presente, apresentam-se os sujeitos da pesquisa. 
Quadro 1: Informações sobre os entrevistados.

\begin{tabular}{|c|c|c|c|c|}
\hline $\begin{array}{l}\text { Narrador } \\
\text { es }\end{array}$ & $\begin{array}{l}\text { Curso Primário } \\
\text { no G.E Uruguai }\end{array}$ & Curso Secundário & Curso Superior & $\begin{array}{c}\text { Atividade } \\
\text { Profissional }\end{array}$ \\
\hline Petronilha & $1949-1953$ & $\begin{array}{l}\text { Ginásio e Científico no Colégio de } \\
\text { Aplicação/UFRGS }\end{array}$ & \begin{tabular}{l}
\multicolumn{4}{l}{ Curso de Letras/UFRGS } \\
Mestrado e $\quad$ Doutorado no \\
PPGEDU/UFRGS
\end{tabular} & $\begin{array}{l}\text { Professora } \\
\text { universitária }\end{array}$ \\
\hline Neusa & $1949-1953$ & $\begin{array}{l}\text { Ginásio no Colégio Nossa Senhora da } \\
\text { Gloria }\end{array}$ & - & - \\
\hline Luiza & $1950-1954$ & $\begin{array}{l}\text { Ginásio no Colégio Bom Conselho } \\
\text { Normal no Instituto de Educação Flores } \\
\text { da Cunha }\end{array}$ & $\begin{array}{l}\text { Curso de Pedagogia/UFRGS } \\
\text { Pós-graduação em Marketing }\end{array}$ & $\begin{array}{l}\text { Funcionária de } \\
\text { empresa } \\
\text { multinacional }\end{array}$ \\
\hline $\begin{array}{l}\text { João } \\
\text { Tadeu }\end{array}$ & $1948-1952$ & Ginásio e Científico no IPA & Curso de Medicina/UFRGS & Médico \\
\hline Aldo & $1949-1954$ & $\begin{array}{l}\text { Ginásio e Científico no Colégio Júlio de } \\
\text { Castilhos }\end{array}$ & $\begin{array}{lccc}\text { Administração } & \text { de } & & \text { Empresas, } \\
\text { Administração } & \text { Pública } & \text { e } & \text { Educação } \\
\text { Física/UFRGS } & & & \\
\end{array}$ & Advogado \\
\hline
\end{tabular}

Fonte: Elaborado pelos autores.

Ao observar essas informações, vê-se que João Tadeu, Neusa e Luiza continuaram seus estudos em instituições privadas. João Tadeu e Aldo tinham a intenção de estudar no Colégio Júlio de Castilhos ${ }^{1}$, entretanto o primeiro não foi aprovado no Exame de Admissão ao Ginásio, diferente de Aldo que concluiu o Curso Científico nesta instituição. Estamos a falar de uma época em que o ensino público era altamente valorizado pela sociedade. Interessante o fato de Petronilha ter ingressado na primeira turma ${ }^{2}$ do Colégio de Aplicação ${ }^{3}$ da UFRGS, provavelmente influenciada pela mãe, professora do Instituto de Educação Flores da Cunha ${ }^{4}$, entusiasta da proposta de ensino diferenciada promovida pelo Colégio de Aplicação. Luiza fez uma trajetória de escola bastante comum às moças de classe média daquela época. Estudou no Colégio Bom Conselho ${ }^{5}$, uma escola católica de moças, e depois Cursou a Escola Normal no Instituto de Educação, dando continuidade a sua formação no Curso de Pedagogia. Entre todos, a única que não prosseguiu seus estudos para além do Curso Ginasial é Neusa, justificou que o casamento e os filhos a impediram de investir na sua formação. Os sujeitos do presente estudo foram alunos de um Grupo Escolar, que estava inserido num cenário em que o rural misturavase com o urbano.

\section{ENTRE A COLÔNIA AFRICANA E O BAIRRO DOS JUDEUS: UMA CASA HABITADA POR UM GRUPO ESCOLAR}

\footnotetext{
${ }^{1}$ Inaugurado no ano de 1900 nas imediações da Faculdade de Direito do Rio Grande do Sul. Sobre o Colégio Júlio de Castilhos, ver Lima (1990).

${ }^{2}$ A primeira turma foi composta por trinta alunos, convidados pela diretora Graciema Pacheco, que não haviam sido aprovados no Exame de Admissão ao Ginásio do Instituto de Educação General Flores da Cunha e do Colégio Estadual Júlio de Castilhos (LIMA, 2016).

${ }^{3}$ Sobre o Colégio de Aplicação, ver Lima (2016).

${ }^{4}$ Sobre a história do Instituto de Educação Flores da Cunha, ver Louro (1986).

5 Fundado pelas Irmãs Franciscanas da Caridade e Penitência, iniciou suas atividades para um público exclusivamente feminino, no ano de 1903. Sobre, ver Bom Conselho (2016).
} 
"Nada de bandidagem, nem de malandragem, a Colônia Africana ${ }^{6}$ era um território de gente trabalhadora, honesta, correta e que estudava [...]" (SILVA, 2010, p. 76). É assim que Jaime Moreira da Silva descreve este amplo território negro, ocupado após abolição da escravatura. Nas primeiras décadas do século XX, era uma região ainda com traços rurais, na qual os casebres da população negra contrastavam com chácaras e seus palacetes. Neste sentido, infere-se que o casarão da Rua Esperança, que se transformou em grupo escolar, era, originalmente, uma residência rural. Entretanto, o processo de urbanização, pouco a pouco, deslocou os negros para áreas periféricas da cidade e, à medida que o século XX avançou, novos grupos étnicos ali se estabeleceram, especialmente, judeus. Era uma região localizada entre os Bairros Bonfim, território dos primeiros judeus da etnia askhenazi ${ }^{7}$ que chegaram em Porto Alegre, e o Bairro Moinhos de Vento, local de moradia de muitos alemães.

Essas são algumas evidências da formação do Bairro Rio Branco, antiga Colônia Africana, onde habitava o Grupo Escolar Uruguai, lugar de moradia dos personagens dessa história, quando eram crianças. Petronilha e Neusa (2016), talvez por ainda residirem no bairro, conseguem traduzir lembranças significativas da antiga Colônia Africana, dizem que além de negros e judeus, o bairro contava com a presença de "poloneses, russos e gente vinda da Argentina". Petronilha (2016) ainda mantém a casa de sua família, originalmente de madeira, construída em 1905, na mesma rua em que estava a escola. Foi lá que nos recebeu para a entrevista. Recorda do ambiente interiorano no bairro, em que todos se conheciam.

A pluralidade étnica se refletia no grupo escolar, pelas narrativas dos entrevistados, percebemos que se referiram à convivência de judeus e negros naquele mesmo espaço. Segundo João Tadeu (2016) "nossos amigos lá no grupo escolar, ou eram negros ou eram judeus". Luiza (2016) comenta que tinha uma amiguinha negra chamada Olga que tinha cheiro de carvão, sua mãe explicou que provavelmente vinha de uma família de lavadeiras que passavam as roupas com ferro a carvão.

Para entendermos o significado de um grupo escolar, naquele contexto tão diverso culturalmente, se faz necessário conhecer alguns aspectos referentes às condições de emergência dos Grupos Escolares ${ }^{8}$. No Brasil, constituem-se como fórmula institucional que

\footnotetext{
6 "A Colônia Africana foi o espaço demarcado pelos libertos do regime da escravidão, na área atualmente denominada Rio Branco, bairro onde se encontram as ruas Cabral (antes Bela Vista), Casimiro de Abreu, Castro Alves, Mariante e Esperança (Miguel Tostes). Em seus limites estavam os arraiais de São Miguel e São Manoel, situados além do Campo da Redenção, longe dos limites da cidade" (BARROSO, 2010, p. 29).

${ }^{7}$ Askhenazi: judeu originário da Europa Ocidental (NOVINSKY; RIBEIRO; GORENSTEIN, 2015, p. 275).

${ }^{8}$ Sobre outros estudos acerca da emergência da escola primária no Brasil, em perspectiva comparada, ver Souza; Pinheiro; Lopes (2015).
} 
sintetizava demandas de racionalização social e escolar e de modernidade pedagógica. Tem como características: seriação, classes homogêneas, ensino simultâneo, regulamentação e uniformização do tempo escolar, enquadramento disciplinar, organização do espaço escolar, etc (FARIA FILHO, 2014). Para o autor, representaram um momento de ruptura com o passado imperial e com as escolas isoladas, afirmando a proximidade e identidade de institutos coletivos de instrução com a modernidade, bem como a institucionalização de uma nova cultura escolar: tempo, espaço e noção de ordem escolar (FARIA FILHO, 2014).

Para Souza (1998), o modelo proposto pelos grupos escolares previa uma série de modificações na organização didático-pedagógica do ensino, entre elas a adoção de espaços específicos e de novos métodos de ensino-aprendizagem, assim como o emprego do tempo, da formação de classes homogêneas, com alunos divididos por idades e por grau de adiantamento, com um professor para cada classe, sob o controle de um diretor, entre outras modificações fundamentadas nas concepções de modernidade e de inovação educacional.

Sobre os grupos escolares do Rio Grande do Sul, são importantes os estudos de Eliane Peres que contextualiza a escola primária nas primeiras décadas do século XX. Segundo a autora, esse período foi decisivo para a escola rio-grandense, pois marca o momento da institucionalização e da difusão de um modelo escolar - o das escolas graduadas, denominadas, no Rio Grande do Sul, de colégios elementares, mais tarde chamados de grupos escolares - e o da expansão do sistema público estadual de ensino. Esse processo de criação dos colégios elementares se deu em 1909, e a implantação desse modelo escolar significou um momento estruturante para o ensino público primário do Estado. Da instalação dos primeiros colégios elementares em 1910 até os anos de 1930 - quando foram, então, indistintivamente denominados de grupos escolares - os governos estaduais ocuparam-se com a expansão paulatina dessas escolas no Estado (PERES, 2010).

Assim, garantir prédios adequados para o funcionamento dos colégios ${ }^{9}$, agrupar os alunos de forma homogênea, designar professoras para cada classe, escolher a direção, fiscalizar o trabalho docente, selecionar os livros didáticos, formular programas e regimentos para o funcionamento desses colégios foram as preocupações iniciais. Muitas dessas preocupações atravessaram décadas sem uma solução adequada, como foi o caso dos prédios escolares (PERES, 2010, p. 68).

A partir de 1939, os grupos escolares, foram gradativamente sendo instalados em todas as cidades do Rio Grande do Sul. Para Peres (2010, p. 74), o ensino primário, sob

\footnotetext{
${ }^{9}$ Sobre a emergência dos prédios e espaços dos grupos escolares no Rio Grande do Sul, ver Ermel (2017).
} 
responsabilidade do Estado, tinha, então, consolidado um modelo escolar que não seria mais abandonado. A partir de então, a denominação das classes passa a ser: $1^{\circ}$ ano, $2^{\circ}$ ano, $3^{\circ}$ ano $4^{\circ}$ ano, $5^{\circ}$ ano.

E justamente em 1939 constituiu-se o Grupo Escolar Uruguai, produto da fusão do Grupo Escolar da Rua Mariante e das Aulas Reunidas da Rua Ramiro Barcelos (SCHUCK, 2008). A escola contava com 12 professores e 260 alunos matriculados (SCHUCK, 2008). Inserido em um bairro peculiar localizava-se o prédio habitado pelo Grupo Escolar Uruguai. Infere-se que se tratava de uma residência rural alugada pelo Estado com a intenção de abrigar a escola.

Durante a primeira metade do século XX, conviviam escolas adaptadas em contraposição aos projetos de construções de grupos escolares segundo modelos que possuíam plantas-tipo $^{10}$, elaborados pela Secretaria de Obras Públicas do Estado.

Na Figura 1, temos a imagem da edificação escolar, em fins do século XIX. Por meio da fotografia, percebemos um palacete que difere das moradias da comunidade negra constantes no entorno, devido a sua imponência. Nota-se um recuo em relação à rua e a existência de um grande jardim na frente do terreno. Esses aspectos estruturais foram mantidos durante o período de ocupação pelo grupo escolar. Na Figura 2, observa-se a fachada da instituição, suas janelas grandes com grades de proteção, escadas em ambos os lados e uma varanda que possuía a finalidade de recepção e acolhimento dos que adentravam o ambiente.

Figura 1: Fotografia da residência da chácara na Rua Esperança (Séc. XIX).

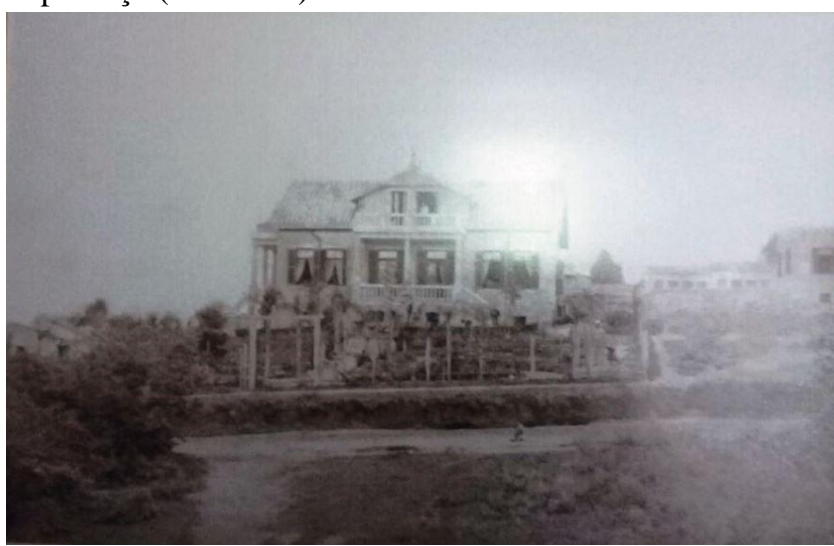

Fonte: Irmãs Servas da Imaculada Conceição.
Figura 2: Fachada do G.E Uruguai (Séc. XX).

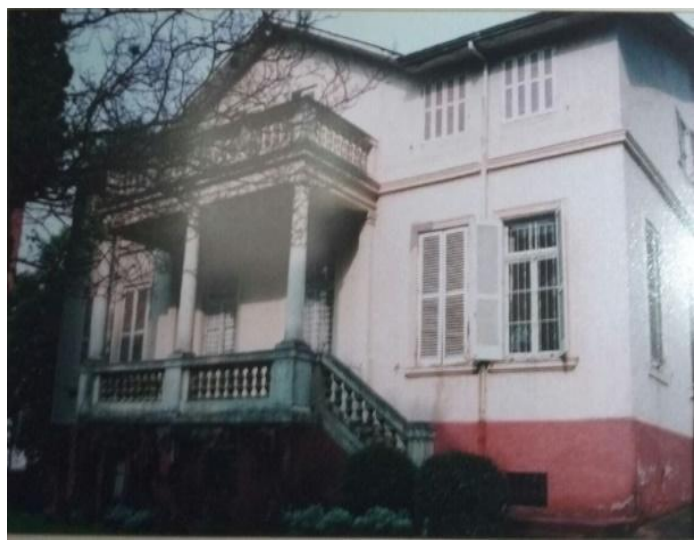

${ }^{10}$ Estes "projetos-tipos" disseminados pelo Estado indicam "uma prática encontrada também em outras províncias brasileiras, na qual um único projeto embasa a construção de vários edifícios" (POSSAMAI, 2009, p. 151).

Rev. Iberoam. Patrim. Histórico-Educativo, Campinas (SP), v. 4, n. 2, p. 236-258, jul./dez. 2018 
A materialidade escolar evoca muitas memórias nos estudantes que por ali habitaram. Petronilha e Neusa narram sobre a fachada e o momento de entrada na escola,

Ao lado direito de quem entra na rua, há ou havia uma escada de mármore que dava acesso a uma sacada. [...] À esquerda do prédio havia outra escada, bem mais alta, que levava a um avarandado onde se encontrava a porta principal, por onde entravam as professoras, as visitas, os pais quando iam fazer a matrícula dos filhos ou tratar de algum assunto de seu interesse. (SILVA; PEREIRA, 2011, p. 154).

De acordo com o excerto, os estudantes entravam por outra porta localizada na lateral da edificação, e que tinha acesso direto ao corredor das salas de aula. Para Ermel (2017), a estrutura de alguns grupos escolares, no Rio Grande do Sul, possuía a separação das entradas entre estudantes e professores, muitos ainda realizavam uma segregação por gênero, infere-se, a partir das narrativas dos entrevistados, que isso não acontecia no G.E Uruguai.

Após a entrada no espaço, tem-se a descrição de Luiza (2016) sobre o seu interior, "no primeiro andar, ficava a secretaria, o $5^{\circ}$ ano, sala de professores, banheiro de professores". Lembra de banheiros específicos para meninos e meninas, porém ressalta que eles não "eram legais" e por isso, preferia usar o dos professores.

Ainda sobre a descrição estrutural, havia salas com pé direito alto, porão e dois andares. Somente João Tadeu e Aldo (2016) afirmaram que havia salas de aula em todos os andares, inclusive no porão, o que pode demonstrar a intenção de otimização do espaço da casa para uma escola. Neste piso localizava-se a cozinha, local onde era servida a merenda. Aldo (2016) recorda, "eu me lembro muito bem do Grupo Escolar Uruguai. Era um casarão antigo. Tinha sala de aula embaixo no porão, tinha sala de aula no meio e tinha sala no sótão também. Te lembra? Lá em cima. Tinha um pátio grande”.

No que diz respeito ao porão da instituição, Neusa e Petronilha (2011, p. 154) descrevem a existência de "um rebaixamento no teto, como se fosse um porão; não se podia passar por ali, pois logo a seguir ficava a residência - sala e quartos - da zeladora chefe da escola, dona Célia, que ali morava com seus filhos". Elas contam que havia uma grande mesa, rodeada de bancos, em que era servida a sopa. Mais adiante, a cozinha com um enorme fogão à lenha, suas grandes panelas e chaleira.

Neste mesmo local, sinalizam a existência de uma abertura na estrutura do prédio, que segundo elas, além de função estética, possibilitava a vigilância dos estudantes e incutia sensações,

Neusa, muito sapeca, um dia se enfiou pelo referido corredor, visitou a casa da tia Célia. Ficou intrigada com uma abertura redonda, como vira em desenho de castelos antigos, e descobriu que através da janela redonda se podia enxergar, sem ser visto, 
tudo que se passava no pátio, o que a criançada aprontava. E ninguém entre os alunos, sabia que aquele lugar existia. (SILVA; PEREIRA, 2011, p. 154).

Os espaços educativos não são neutros, são um "constructo cultural que expressa e reflete para além de sua materialidade, determinados discursos" (ESCOLANO, 2001, p. 26). Esses lugares também atuam como meio de controle dos estudantes. Além disso, evocam sensibilidades nas memórias das entrevistadas.

\begin{abstract}
Mas o que mais a impressionou na visita foi descobrir que embaixo da escola, num espaço pequeno e espremido, morava uma família. Teve medo e incompreensão, voltou para casa pensando. E até hoje lembra e sente novamente um aperto, uma tristeza: como podia, naquela escola enorme, morarem pessoas embaixo, em um porão, num pequeno espaço. (SILVA; PEREIRA, 2011, p. 154).
\end{abstract}

No relato acima, temos uma profusão de sentimentos que emergiram a partir da rememoração desses espaços. Este relato, por outro lado, foi dissonante no conjunto das memórias analisadas, pois a maioria idealiza e representa a espacialidade escolar como algo "maravilhoso". Nesta perspectiva, apareceram as reminiscências referentes aos momentos e espaços de diversão: À direita de quem vinha da rua, encontrava-se a cancha utilizada para os jogos de bola, vôlei, caçador durante as aulas de Educação Física. João Tadeu e Aldo (2016) ocuparam um tempo da entrevista descrevendo o pátio, e o campo de futebol nos fundos, um lugar muito importante para eles, lugar de brincar. Lembram também que costumavam frequentar a escola fora do horário de aulas para jogar vôlei.

Os entrevistados contam que, quando lá estudavam, o prédio já indicava sinais que precisava de reparos, tendo em vista que era um lugar adaptado para o funcionamento de uma escola. No início da década de 1970, a escola foi transferida para um prédio construído especificamente para abrigá-la, mantendo-se no mesmo bairro. Sobre a edificação na Rua Esperança sabe-se ${ }^{11}$ que foi comprada pela Congregação das Irmãs Missionárias de São Carlos Borromeo Scalabrinianas $^{12}$, mas, somente no ano de 2008, passou por uma reestruturação com finalidade de tornar-se a residência provincial.

\title{
MEMÓRIAS DO GRUPO ESCOLAR URUGUAI
}

O desafio desta pesquisa que opera com a metodologia da História Oral está em produzir uma narrativa inteligível, tramando o que disseram esses antigos estudantes nos eventos das entrevistas. Portanto, o que nos moveu foi a intenção de escrever uma versão da história de uma

\footnotetext{
${ }^{11}$ Essa informação foi obtida por meio de uma visita à sede da Congregação, hoje rua Miguel Tostes n ${ }^{\circ} 187$.

12 Sobre a história da congregação, ver Signor (2007) e Belusso (2016).
} 
instituição escolar específica, o Grupo Escolar Uruguai. Produzimos uma representação historiadora, tendo como ancoragens os modos como os sujeitos da pesquisa representaram o seu passado. Desse modo, a seguir, articulam-se os documentos orais em categorias que analisam memórias das liturgias da escola, das professoras e das práticas escolares.

\section{Liturgias da escola}

De tudo o que escutamos, percebemos uma série de liturgias que indicam determinados rituais intrínsecos à escolarização que permeavam o cotidiano nos grupos escolares, e hoje se manifestam como pregnâncias nas memórias dos antigos alunos. Pode-se pensar que nas aulas isoladas esses rituais fossem mais singelos, mas, à medida que a escola republicana se institucionalizava como espaço formativo de cidadãos, se fez necessário o investimento em muitos aspectos simbólicos que, pela recorrência em que aconteciam, marcam as memórias daqueles que passaram pelos grupos escolares. Boto (2014), ancorada em Elias (1993), faz pensar no processo civilizador como constituinte do conceito de escola moderna emergente no século XX. Esses rituais instituem processos de civilidade, com vistas a produzir a autorregulação dos sujeitos discentes.

Assim, procuramos identificar quais indícios de liturgia escolar emergiram nas entrevistas. Eles lembraram que o deslocamento pela escola em direção ao interior do prédio se dava em filas por turmas, que partiam do pátio, organizadas por altura. Como disse João Tadeu (2016) "e aí tinha que pôr a mão no ombro do outro pra dar uma distância”. Nas salas de aula, disseram que meninos e meninas se sentavam misturados, entretanto havia divisão dos lugares de acordo com o entendimento da professora quanto à capacidade de cada criança acompanhar as aulas, se formavam as filas dos "adiantados, dos médios e dos atrasados" (SILVA; PEREIRA, 2011).

Petronilha contou que costumava estar na fila dos adiantados que ficava mais próxima dos janelões, sempre abertos, todavia, uma vez ficou doente e, ao retornar para a escola, não pode sentar-se no lugar de costume. Em função de estar se recuperando, teve que juntar-se aos "atrasados". Segundo as entrevistadas, podia-se trocar de posição na sala, conforme as habilidades fossem melhores em leitura, por exemplo, mas não tão boas em aritmética.

Pelas informações trazidas sobre os horários das aulas, percebe-se que havia uma otimização do tempo escolar, pois eram três os turnos de estudo. Pela manhã, das $8 \mathrm{~h}$ às $11 \mathrm{~h}$, depois outro turno no horário das $11 \mathrm{~h}$ às $14 \mathrm{~h}$ e, por fim, um vespertino, das $14 \mathrm{~h}$ às $17 \mathrm{~h}$. Passavam-se três horas na escola, um tempo reduzido se observarmos a carga horária dos 
estudantes contemporaneamente. Não se nota um entendimento comum a respeito de quem estudava pela manhã ou pela tarde, mas houve consenso em identificar o horário intermediário como aquele destinado aos alunos repetentes. Aquela era outra época, as relações no mundo do trabalho não eram as mesmas de hoje e, provavelmente, havia distintos arranjos familiares no cuidado com as crianças. E o que pensar sobre um horário exclusivo para aqueles que reprovavam no ano escolar? Essa nos parece uma prática que oferece indícios de uma discriminação entre os alunos, pois, segundo as narrativas, aqueles que não avançavam nos anos escolares, deveriam frequentar a escola em um horário, separados dos demais.

A escola graduada se constitui na Modernidade como um lugar de controle e busca pela homogeneização (VARELA; URIA, 1992). Uma prática ritualística que define a identidade do estudante e do professor é o uso do uniforme, obrigatório no G.E Uruguai, recordado com detalhes pelos narradores: guarda pó branco com o monograma da escola, o dos meninos atingia a altura dos quadris, o das meninas devia cobrir a saia, tinha pregas e um cinto. $\mathrm{Na}$ altura da gola, os meninos usavam uma gravata e as meninas um laço azul-marinho. Em relação aos calçados, disseram que eram exigidos sapatos pretos no uso diário e, para as aulas de Educação Física, tênis branco. As professoras usavam avental de tecido xadrez azul marinho e branco, também bordado com o monograma da escola (SILVA; PEREIRA, 2011).

Petronilha (2016) recordou de uma docente que, em ocasiões festivas, alertava as crianças "amanhã vocês têm que tomar banho, colocar perfume, ficar bem limpas". Ao chegar em casa, contava à sua mãe e esta dizia: "algum dia tu foste à escola sem tomar banho? Algum dia tu foste com o uniforme sujo? Então, esse recado não serve".

Outras práticas ritualísticas evocadas foram as ações cívicas, com destaque ao Hino do Uruguai, costumeiramente entoado em comemorações da escola. As entrevistadas disseram que na Semana da Pátria sempre havia uma solenidade na escola para receber o fogo simbólico que se instalava perto da sala da diretora e era guardado por dois alunos de diferentes turmas, substituídos a cada 30 minutos. Neusa (2016) falou de seu orgulho ao participar da guarda da tocha, conta que algumas crianças passavam pela pira e faziam caretas para aqueles que estavam na vigília. Ela tinha que se conter para não cair na gargalhada, em função do controle das professoras que por ali estavam. Nesta perspectiva, Carlota Boto (2017/2014) discute o significado dos atos litúrgicos constitutivos dos processos de escolarização. Segundo a autora, "a escola compõe, por seus fazeres e haveres, uma forma de liturgia" (BOTO, 2014, p. 102). Assim, a memória coletiva dos antigos estudantes indicou os modos de como a escola, por meio da sua normatividade, fomentava o processo civilizador. 


\section{Por dentro da escola: professoras e práticas escolares}

As memórias dos sujeitos da pesquisa narram uma escola impregnada de conceitos próprios de uma época de consolidação dos grupos escolares, como instituições públicas de ensino. Aqui nos propomos a discutir as impressões desses antigos alunos a respeito das práticas educativas desenvolvidas no G.E Uruguai. Algumas dessas práticas ainda são comuns, enquanto outras nos parecem estranhas, dadas as transformações vividas na escola contemporânea.

O exercício da rememoração faz emergir do esquecimento memórias relacionadas às professoras. Os entrevistados, como sujeitos escolarizados, passaram um tempo importante de sua infância dentro do Grupo Escolar. Se para os docentes pode ser difícil identificar antigos alunos, isto tende a não ocorrer quando são os estudantes que evocam seus professores. Neste sentido, Halbwachs (2004) analisa as diferenças das memórias entre quem, em tese, ensina e aprende. $\mathrm{O}$ autor justifica essas diferenças do lembrar, considerando uma questão quantitativa, aquele que ministra aulas têm muitos alunos e estes, ao longo da vida escolar, passaram por alguns professores. É nesta perspectiva que os entrevistados descreveram detalhadamente suas antigas mestras. Mas, é Luiza (2016) quem consegue elencar os nomes de todas elas e suas respectivas séries: "professora do primeiro ano, Dona Nilsa, maravilhosa; segundo ano, Dona Beloni; terceiro ano, Dona Maria de Lurdes; quarto ano, Dona Luci e quinto ano, Dona Cecí”.

Em um ambiente feminizado, ninguém recorda de homens na escola, nem mesmo a figura da diretora era masculina. Contudo, lembram de duas professoras negras, "Dona Aracy e Dona Helenita", uma informação importante do ponto de vista étnico racial, que oferece indícios para entender o magistério como uma profissão não ocupada majoritariamente por mulheres brancas.

Neusa (2016) refletiu sobre o sentimento de respeito que as crianças tinham diante das professoras. Ao ser indagada se eram rígidas, argumenta: "severas não, elas queriam o que tinha que ser na sala de aula. A gente não tinha medo delas. Nossa, encontrar uma professora na rua era a mesma coisa que hoje aquelas gurias que ficam gritando pelos artistas". Neste sentido, uma forte presença nas memórias dos depoentes é "D. Jovita" à frente da direção da instituição. Luiza diz que "ela era uma pequenininha, [...] mas quando entrava, enchia uma sala. E no tempo que professor ou diretor entravam na escola, a gente levantava, [...] e ficava até que mandassem sentar". Interessante a história contada por Aldo que reforça a importância de Jovita em sua escolarização. Ele não parou de elogiá-la ao longo da entrevista. Uma de suas travessuras era não usar a escada para deslocar-se e sim descer por um barranco, segundo ele "era mais rápido". 
Em um desses episódios, ele e outros meninos caíram por cima de um muro que desencadeou um acidente, uma menina quebrou a perna. Aldo resume o desfecho dessa história, a diretora teria dito para ele: "Procura outra escola". Foi estudar no Colégio Rosário ${ }^{13}$. Passados alguns meses, não se adaptou à instituição marista e procurou a diretora do Uruguai para pedir seu reingresso: "professora Jovita, eu vou me comportar. No fim, ela me aceitou de volta. Era uma grande, grande professora! Compreensiva!” A narrativa de Aldo faz pensar na sensibilidade daquela mulher que ocupava o lugar da direção do grupo escolar, pois, ao final, aceitou o aluno de volta. Talvez por isso o nome de Jovita lhe desperte tamanha comoção.

Ao falarem sobre as aulas, nossos entrevistados afirmaram que havia a unidocência, todavia, contava-se com outras docentes especializadas para as aulas de Desenho, Trabalhos Manuais, Educação Física e Música. Observa-se uma recorrência positiva das aulas de desenho nas memórias dos estudantes. Destacam as saídas ao Parque da Redenção, quando a atividade consistia em observar a paisagem e produzir desenhos. Petronilha (2016) explicou que no quarto ano as meninas, aprendiam a bordar e fazer crochê, enquanto os meninos faziam seus trabalhos manuais utilizando madeira, serras e pirógrafo. Em dezembro, uma exposição apresentava à comunidade a produção dos estudantes. Ela e Neuza destacaram os trabalhos com couro, madeira compensada e pirogravura, além das dobraduras. João Tadeu (2016) diz "eu devia ter trazido um abridor de cartas com pirogravura, que eu fiz lá" e Aldo (2016) complementa "tinha até pouco tempo uma caixinha de joias que a gente fazia".

Enquanto Petronilha, Neusa e Luiza conseguiram rememorar aspectos pedagógicos da sala de aula, como o uso de livros didáticos e cadernos, entre outros, para Aldo e João Tadeu, o que mais marcou foram essas saídas para o Parque da Redenção, as aulas de trabalhos manuais, além das atividades de Educação Física. Como entender essas particularidades, sem esbarrar em um reducionismo de diferenças sexistas? Talvez se possa pensar que, sobretudo, naquelas décadas, meninos e meninas eram educados de modos muito distintos e isso se dava tanto em casa como na escola. Por que, nesse estudo, os homens valorizaram as travessuras, os esportes e as atividades ao ar livre, ao passo que as mulheres falaram dos cadernos que eram passados a limpo, das práticas de leitura, dos detalhes dos uniformes e das composições?

É assim que as três narradoras afirmaram o quanto apreciavam as aulas de Língua Portuguesa. Petronilha (2016) complementou que a prática das composições era algo frequente na escola, sendo quase diária. Eram escritas em folhas que, ao final, a professora recolhia. Luiza

\footnotetext{
${ }^{13}$ Fundado pela congregação Marista, no ano de 1904, para um público exclusivamente masculino. Sobre, ver Rodrigues (2004).
} 
(2016) também se referiu às composições e explica como aconteciam: "e era assim ó: ou ela contava uma metade de história ou ela botava uma gravura e pedia para desenvolver o texto". Lembrou também da composição oral, que depois era transformada em escrito, que, segundo a narradora, deixava claro aos estudantes que o texto deveria ter início, desenvolvimento e fim. As três rememoraram que essa prática escolar sempre comparecia nos exames avaliativos, normalmente apresentava-se uma gravura aos estudantes e estes tinham que discorrer sobre a mesma.

Aldo e João Tadeu (2016) também se posicionaram sobre suas preferências quanto às disciplinas escolares. João Tadeu sempre reforçando o significado dos trabalhos manuais, hoje, médico aposentado, se dedica à escultura. Aldo, da mesma forma, destacou os trabalhos manuais, mas não esquece as aulas de Matemática e de Educação Física, muitos anos depois, cursou a Faculdade de Educação Física.

Sobre as avaliações, Petronilha (2016) acrescentou que eram feitas pelo $\mathrm{CPOE}^{14}$, padronizadas, aplicadas por professoras de outras escolas. Completa dizendo que as professoras se reuniam no Colégio Rio Branco ${ }^{15}$ e lá corrigiam as avaliações que vinham de outras escolas. Afirma que quando criança sabia desses detalhes, pois sua mãe era professora pública e explicava esses meandros do processo avaliativo à filha.

Luiza, Petronilha e Neusa (2016) comentaram que se fazia "provas" de todas as atividades, inclusive de desenho, trabalhos manuais e dobradura. Como orientação prévia para o estudo, Neusa (2016) lembrou que as professoras assim diziam: "vocês têm que estudar tal coisa e tal coisa". Luiza, graduada em Pedagogia, criticou aquele modo de avaliar, que, segundo ela, consistia em uma única avaliação, a sabatina. Disse que tinha facilidade em Português e História. Não gostava de Geografia e Ciências, "mas a minha tragédia era Matemática e aí, quando eu ia pro vermelho, me botavam em professora particular". Interessante o fato de duas entrevistadas fazerem referência à prática das famílias de buscarem auxílio particular para aquilo que não era perfeitamente assimilado na escola, pois Neusa (2016) também comenta que recorrentemente tinha aulas particulares com a mãe de Petronilha.

Em relação ao dever de casa, Luiza (2016) recordou das inúmeras vezes que enchia os cadernos com conjugações verbais. Lembra também das cópias do quadro, sistemáticas e cansativas, segundo ela "tu lia na aula e tinha que copiar, depois tu chegava lá e ainda tinha que ler em voz alta".

\footnotetext{
${ }^{14}$ Centro de Pesquisas e Orientação Educacional - CPOE, da Secretaria de Educação e Cultura do Rio Grande do Sul. Atuou de 1942 a 1971. Sobre, ver Quadros (2006).

${ }^{15}$ Escola Estadual de Ensino Fundamental e Médio, localizada no Bairro Santa Cecília, em Porto Alegre.
} 
$\mathrm{Na}$ esteira dessas memórias, foram evocados o uso do lápis e da caneta. Luiza (2016) explica que primeiramente usava-se o lápis e, a partir do terceiro ano, começava-se a escrever com caneta tinteiro. Ressalta que havia dois cadernos, um que era uma espécie de rascunho e outro "caderno de verdade", com as atividades passadas a limpo em casa. Ao ser perguntada se isso levava muito tempo, afirmou que sim, "por isso que a gente passava a tarde em cima dos livros."

Um aspecto curioso narrado por elas é o "superapontador de D. Jovita", que, de acordo com Luiza (2016), ficava "preso na ponta de uma mesa da sala que ela dividia com a secretária da escola, D. Helga". Disseram que, quando precisavam, pediam autorização à professora e iam apontar seus lápis e, nessas oportunidades, a Diretora aproveitava e "pedia que lessem alguma coisa ou que resolvessem alguma continha", enquanto os lápis iam sendo apontados (SILVA; PEREIRA, 2011, p. 157).

Um lugar da escola que despertou emoções nas três entrevistadas ao ser evocado foi abiblioteca, associada às práticas de leitura desenvolvidas. Semanalmente, contaram que as professoras levavam as turmas para retirada e devolução de livros. Petronilha e Neusa explicaram, "cada livro era um encanto, uma viagem entre castelos e magias, como as de Tibicuera, contadas por Érico Veríssimo, a valentia de Joana D’Arc, a história do Brasil contada por Viriato Correa. Também liam Monteiro Lobato" (SILVA; PEREIRA, 2011, p. 157).

Para Faria Filho (2014), a biblioteca é o local que se destina às atividades de leitura e pesquisas escolares, assim, o espaço assume aproximação com os alunos, professores e se potencializa com o mundo urbano. Mesmo estando localizada no interior dos grupos escolares, ela acaba adquirindo outros significados, por haver uma proximidade entre as moradias e a escola, resultando também na utilização pela comunidade.

Neusa explicou que gostava de retirar livros de fadas que sua avó lia para ela, lembrou também que recebia como presentes de Natal outros livros de fadas em que o príncipe virava sapo, "aquilo tudo mexia com a minha cabeça". Ela complementou apontando a circulação de livros, "também acontecia que quando uma lia, já dizia: 'bah, tu tem que pegar aquele livro". Quando questionamos se havia obrigação de retirada de livros na biblioteca, ambas não entendem dessa forma, Petronilha (2016) argumentou que "era hora de biblioteca e a gente ia lá e trocava os livros". E Neusa completou "vinha pra casa faceira com os livros. E a própria dona Beloni incentivava: ó tu já levou esse, leva outro, esse aqui é muito bom.”

Diferente delas, Luiza lembrou a quantidade de livros em sua casa e o quanto a leitura era algo que a movia, nesse sentido, ressaltou o significado de ter sido iniciada na leitura e 
escrita no Grupo Escolar Uruguai. Mas, ao ser questionada sobre os usos da biblioteca, demonstra um outro entendimento distinto do que foi dito pelas duas alunas anteriormente.

Eu gostava da biblioteca, mas eu tinha uma excelente biblioteca em casa. Pra estudos e pra livros, na minha casa não tinha restrições. E os meus livros eram muito bem cuidados. E eu ficava um pouco chateada de ir à biblioteca. Tinha variedade, eles levavam a gente, mas eu achava os livros mal cuidados, claro, eram livros manuseados, né? Mas era bom, era bem dirigida, tinha uma bibliotecária e ela nos ajudava. A biblioteca era usada sim pra lazer. (LUIZA, 2016).

O que se pode inferir? Eram meninas com uma situação de vida distinta, se tomarmos como referência um ponto de vista econômico. É possível que, diferente de Luiza, Petronilha e Neusa não tivessem a mesma oferta de livros em casa. Por isso, o encantamento das duas meninas negras com o lugar dos livros no Grupo Escolar Uruguai que lhes permitia transpor o ambiente escolar e viver outras experiências por meio das práticas de leitura.

Além das práticas educativas já comentadas, destaca-se a emergência dos pelotões de saúde, produtos das tendências higienistas, identificados aos princípios da medicina atrelados à educação. Luiza (2016) foi a única entrevistada que conseguiu trazer essas informações, explicando como se desenvolviam os pelotões no colégio. Diz que era escolhida como uma espécie de monitora, devido à sua aparência, tendo unhas bem cortadas, orelhas limpas, cabelo lavado. Mas não se esquece do constrangimento que sentia ao ter que se colocar em uma posição de autoridade em relação a seus colegas, "eu só brigava na hora da fila que eu queria que fizessem uma fila direita. Mas aí, teve o desfile e esse pelotão foi todo vestidinho de enfermeira, que, na verdade, era o próprio guarda-pó, só que com um chapeuzinho de enfermeira”. Em suas relíquias, guarda a foto deste momento:

Figura 3: Pelotão de saúde.

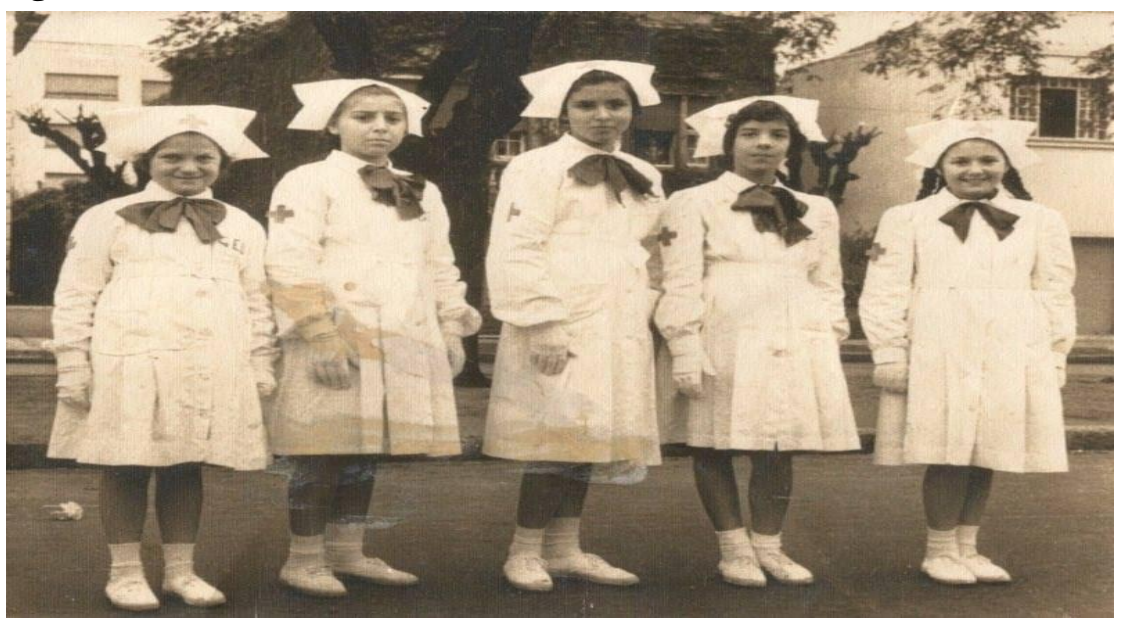

Fonte: Acervo de Luiza Chagas. 
A saúde do corpo por meio da higiene é uma questão constitutiva dos grupos escolares e considerada determinante no processo formativo das crianças. Portanto, os prédios escolares deveriam contar com gabinetes médicos e dentários, que, segundo Vidal e Faria Filho (2005), eram requisitos das construções escolares desde os anos de 1910. De acordo com Zen (2006, p. 2332), esses espaços auxiliares eram constituídos de grupos organizados no interior das instituições escolares, fossem elas públicas ou particulares, com um propósito comum de integrar o corpo discente, estimulando uma formação cívica, moral e intelectual por meio do exercício de "atitudes de sociabilidade, responsabilidade e cooperação", contribuindo igualmente com o processo de busca por uma identidade nacional.

Os entrevistados recordam a existência desses espaços inseridos no interior do Grupo Escolar, falam que os estudantes eram sistematicamente examinados e muitos eram orientados a tomarem a sopa da escola, possivelmente por estarem abaixo do peso adequado para a idade. Além disso, eram oferecidas vacinas, como contra a varíola. O dentista aplicava flúor nos dentes e tratavam-se as cáries. Petronilha salienta que a filha da diretora Jovita se formou médica e virou doutora do grupo escolar. Isso faz pensar numa certa intimidade no espaço público de trabalho, em que mãe e filha desenvolviam suas atividades, embora distintas.

Os clubes agrícolas também eram espaços difundidos nos Grupos Escolares, cuja finalidade era fomentar na infância o gosto pela agricultura em suas mais variadas particularidades. Buscavam a promoção do sentido de cooperação, pois as atividades seriam desenvolvidas coletivamente. Petronilha e Neusa (2011, p. 155) explicaram que nos fundos do prédio da escola havia uma horta, cultivada pelos alunos maiores sob a orientação das professoras, e cuidada pelas zeladoras. Esses espaços cumpriam um papel educativo, além de garantir legumes e verduras frescas para a sopa distribuída aos alunos.

As aulas de Religião são um tema que emergiu nas narrativas. O Estado republicano, laico, ainda assim mantinha esse tipo de formação nas escolas públicas, herança de um passado colonial, marcadamente jesuítico, que ecoa nas memórias dos sujeitos entrevistados. Essas lembranças apareceram justamente quando falaram da expressiva presença de estudantes judeus na escola. Luiza criticou a professora, "D. Araci que falava muito em diabo [...] eu não gostava daquilo porque se tinha uma criança um pouco mais arteira na aula, tá com o diabo no corpo. $\mathrm{E}$ meus colegas judeus tinham que ficar assistindo as aulas de Religião".

A questão que se coloca é: seria essa uma postura isolada dessa docente rememorada por Luiza? Ou seria comum a segregação na escola às comunidades étnicas? E em relação aos negros? O que se percebe é que na Colônia Africana houve uma adesão ao catolicismo, é possível que as religiosidades de matriz africana não tivessem tanta força naquela região, talvez 
fossem mais perseguidas ainda pela sociedade branca e católica. A mesma antiga aluna expõe um episódio que envolve as crianças de origem judaica: "e um dia, quando estava próximo da Páscoa, ela falou que os judeus tinham matado Jesus e todo mundo se encolheu, né? Eu não gostava dessa professora, porque eu me sentia tão constrangida de ver meus colegas num ladinho assim sabe?

Entretanto, Aldo e João Tadeu disseram não lembrar que tais situações ocorressem na escola. Mas recordam que na rua era comum fazerem um boneco, "Judas" e o queimarem na Páscoa, assim diz João Tadeu "a gente fazia o boneco e malhava, batia e depois queimava o judeu". Nesse meio tempo, Aldo pediu para perguntarmos a João Tadeu qual era seu apelido na escola, João respondeu "judeu”, em função da fama se ser sovina. Aldo justifica "é que eu me dava muito com os judeus e tinha a cara muito sardenta também quando pequeno". Essas são algumas evidências que permitem entrever o quanto a convivência entre diferentes grupos étnicos não é algo simples de se entender. A escola pública, pelos indícios apresentados, ainda precisaria avançar muito no respeito às diversidades culturais.

Quando indagados se havia crianças pobres na escola, houve divergências, Petronilha, por exemplo, disse que não, e aproveita para trazer as palavras de sua mãe, que sempre afirmava diante da filha "nós somos pobres, não somos miseráveis". Essas lembranças evocaram a prática da Caixa Escolar, a qual era custeada pelas famílias. A escola promovia atividades que arrecadava fundos para a Caixa, como a exibição dos filmes aos sábados na parte final da manhã, em que cada estudante, se pudesse, contribuía com uma pequena quantia. A Caixa, portanto, ajudava na compra de materiais escolares, uniformes, até mesmo calçados para quem não os tinha. Petronilha explicou seu funcionamento, trazendo a situação de uma família que não tinha condições de comprar os livros didáticos, "e aí na secretaria eles organizavam as coisas. E a criança nem ficava sabendo. Perguntava: por que não tem o livro? E a criança dizia: 'ah, a mãe ainda não deu pra comprar'. Daí a mãe ia ou a criança ia na Caixa Escolar’. Essa é uma situação que permite perceber o quanto a comunidade escolar se organizava e desenvolvia estratégias para resolver os problemas dos mais necessitados, sem contar com o suporte do Estado.

De modo geral, os entrevistados evocaram muitas memórias alegres dos tempos vividos no Grupo Escolar Uruguai. No entanto, ressentimentos foram relatados por Neusa e Petronilha. Neusa conta que havia sido escolhida para representar a turma em uma apresentação, para tanto, ensaiou muito, mas, às vésperas da cerimônia, foi dispensada, “então me dediquei, né? E daí na hora entrou uma outra menina e eu não fui. E eu queria saber por quê. A minha família deduziu 
que era o preconceito velado. Eu fiz tudo... e na hora assim, tu não ir? Ficou muito marcado pra mim, com essa professora. A professora Aline".

Talvez entusiasmada pelo relato da amiga, Petronilha também narrou uma história triste:

No primeiro ano que era pra desfilar, ela disse que eu não sabia marchar direito. Ah, fiquei pra morrer porque não ia desfilar. Aí, não sei se faltaram crianças e ela disse que eu ia desfilar e que não podia não ir. Daí a minha mãe disse: "não, se tu não podias antes, agora não pode e tu não vais, qualquer coisa que aconteça eu vou lá no colégio". Evidentemente, não aconteceu nada e ninguém perguntou por que eu não fui.

Chama a atenção que foram justamente essas duas mulheres negras, Petronilha e Neusa, as narradoras de memórias ressentidas. Seria essa uma mera coincidência? Ou mais uma situação de preconceito na escola, neste caso, preconceito étnico-racial?

As práticas desenvolvidas nos grupos escolares e trazidas pelos narradores constituíramse em um instrumento nacionalizador e formador de uma identidade brasileira que se pretendia reforçar nessas instituições de ensino. É assim que os trabalhos manuais, os passeios, as atividades de leitura e escrita, os pelotões de saúde, a Caixa Escolar, as aulas de Religião, a horta, entre outras lembranças afloraram no momento em que conversamos sobre o Grupo Escolar em que estudaram.

\section{CONSIDERAÇÕES FINAIS}

Historiar uma instituição educativa é tarefa minuciosa. A História da Educação como campo temático de investigação lança olhares distintos ao espaço escolar e se debruça sobre a cultura, a partir de normas e práticas que levam em conta os agentes envolvidos no processo de educar (JULIA, 2001).

Neste texto, versões do passado pelo olhar de cinco estudantes do Grupo Escolar Uruguai, foram tecidas e tramadas com o objetivo de compor e problematizar o que foi escolhido para ser lembrado. Esta pesquisa, entre outras possibilidades, fez uma escolha metodológica que elegeu como documentos as narrativas de homens e mulheres longevos, valorizando suas percepções acerca dos meandros das práticas escolares.

Nos encontros em que se partilharam conversas e escutas, eles e elas rememoraram um tempo de outrora, quando brincavam pelas ruas, andavam de bicicleta e de carrinho de rolimã. Na escola, tomavam a sopa, jogavam caçador, cuidavam da horta, entre tantas reminiscências. Evocaram uma outra Porto Alegre dos anos 1940 e 1950, especialmente memórias da Colônia Africana e de um casarão instalado na região. 
Neste sentido, consideramos a força da memória coletiva, é Halbwachs (2004, p. 31), quem diz "outros homens tiveram essas lembranças em comum comigo". De certo modo, é como se eles falassem todos juntos, pois encontramos mais recorrências do que dissonâncias.

A adoção dos grupos escolares significou um momento de ruptura, de recriação da educação escolar no contexto do ensino primário. E esse período da história da escolarização leva a compreender como um momento do processo da crescente racionalização e urbanização da sociedade.

A representação dos grupos escolares fundamentou-se discursivamente pelo tripé "moral, higiene e estética" (NUNES, 2007, p. 385) que legitimou a sustentação pedagógica desse modelo de escola seriada, que pretendia colocar as escolas isoladas como símbolo do passado. Buscava-se moldar as práticas, os ritos e os símbolos escolares, produzindo uma nova identidade para os sujeitos que ocupavam os bancos da escola pública, vinculando-os com o "mundo secular público e urbano" (FARIA FILHO, 2014).

As narrativas de memórias desta pesquisa evidenciam como reelaboram o tempo vivido naquele espaço. De modo geral, as principais características dos grupos escolares, envolvendo liturgias e práticas, compareceram nos relatos dos personagens dessa história. Estudaram em um prédio adaptado para uma escola, em que havia horta, biblioteca, merenda, gabinetes médico e dentário, várias professoras, uma diretora, rituais cívicos, exames de avaliação padronizados, classes seriadas, práticas esportivas, uniformes, horários das aulas.

Algo que merece atenção é o fato de que os negros estavam efetivamente frequentando essa escola, seja na condição de alunos ou professores. Não podemos esquecer que o Grupo Escolar estava inserido na Colônia Africana. Entretanto, é Petronilha que chama a atenção para o fato de muitos negros ingressarem tardiamente na escola e também destaca que havia um alto índice de evasão entre eles, que partiam em busca de trabalho, antes de concluírem o Curso Primário. Este nos parece ser um aspecto importante, para não pensarmos que havia uma equidade entre a população negra e branca na escola pública. Também é importante salientar que estamos falando de uma instituição de ensino primário. Seria importante saber em que medida a população da Colônia Africana conseguiu dar continuidade em seus estudos em outros espaços escolares.

Lembranças sobre o tempo vivido na escola são carregadas de representações. Os cinco estudantes do Grupo Escolar Uruguai, cada um a seu modo, idealizam uma escola "maravilhosa", em que há pouco espaço para os ressentimentos. A capacidade de todos nós fabularmos o passado é própria da condição humana. Eles e elas, pessoas maduras, nos apresentaram memórias afetivas, memórias de um tempo em que eram crianças e que tiveram 
sua iniciação escolar em uma instituição afinada com um novo modelo de formação de um cidadão brasileiro.

Voltando à epígrafe que abre este texto, o poema de Cora Coralina nos remete às memórias do ensino primário. Os espaços compartilhados do casarão da Rua Esperança, das salas de aula, do pátio e dos corredores entremeados às lições e aos nomes dos colegas, ao quadro-negro, à caneta tinteiro, ao caderno borrado. Tudo isso emerge nas memórias dos antigos estudantes inscrevendo as experiências escolares da infância entre as marcas do passado e as horas do relógio.

\section{REFERÊNCIAS}

BARROSO, Véra Lúcia Maciel. Porto Alegre: funções e papéis de uma cidade polo. In: POSSAMAI, Zita Rosane (Org.) Leituras da cidade. Porto alegre: Evangraf, 2010.

BELUSSO, Gisele. Colégio Nossa Senhora de Lourdes, Farroupilha/RS: histórias de sujeitos e práticas (1922-1954). 2016. 239 f. Dissertação. (Mestrado em Educação) - Programa de Pós-Graduação em Educação, Universidade de Caxias do Sul, Caxias do Sul, RS.

BOTO, Carlota. A liturgia da escola moderna: saberes, valores, atitudes e exemplos. Hist. Educ. [Online]. Porto Alegre, v. 18, n. 44, p. 99-127, set./dez. 2014.

BOTO, Carlota. A Liturgia Escolar na Idade Moderna. Campinas: Papirus, 2017.

BOSI, Eclea. Memória e Sociedade: Lembranças de velhos. São Paulo: T.A. Editor, 1979.

COLÉGIO BOM CONSELHO. Nossa História. Disponível em: <http://www.bomconselho.com.br/>. Acesso em: 19 dez. 2016.

CORALINA, Cora. Poemas dos becos de Goiás e estórias mais. São Paulo: Global, 1985.

ELIAS, Norbert. O processo civilizador. Rio de Janeiro: Zahar, 1993. (V. 2)

ERMEL, Tatiane de Freitas. Arquitetura Escolar e Patrimônio Histórico-Educativo: Os edifícios para a Escola Primária Pública no Rio Grande do Sul (1907-1928). 2017. 343 f. Dissertação. (Mestrado em Educação) - Programa de Pós-Graduação em Educação/PPGE, Pontifícia Universidade Católica do Rio Grande do Sul, Porto Alegre, RS.

ERRANTE, Antoinette. Mas afinal, a memória é de quem? Histórias orais e modos de lembrar e contar. História da Educação, UFPel, Pelotas, v. 4, n. 8, p. 141-174, set. 2000.

ESCOLANO, Agustin. Arquitetura como programa. Espaço-escolar e currículo. IN: VIÑAO FRAGO, Antonio; ESCOLANO, Agustín. Currículo, Espaço e Subjetividade: a arquitetura como programa. Rio de Janeiro: DP\&A, 2001. 
FARIA FILHO, Luciano Mendes de. Dos pardieiros aos palácios: cultura escolar e urbana em Belo Horizonte (1906/1918). 2. ed. Uberlândia: EDUFU, 2014.

HALBWACHS, Maurice. A memória coletiva. São Paulo: Centauro, 2004.

JOÃO TADEU E ALDO. Entrevista II. [Nov. 2016]. Entrevistadoras: Alice Jacques e Dóris Almeida. Porto Alegre, 2016.

LIMA, Otávio Rojas. (Org.). Memórias do "Julinho": Colégio Estadual Júlio de Castilhos 1900-1990. Porto Alegre: Sagra, 1990.

LIMA, Valeska Alessandra de. Colégio de Aplicação da UFRGS: práticas educativas adormecidas entre o Arquivo e a Memória Oral (1954-1981). 2016. 122 f. Dissertação (Mestrado em Educação) - Programa de Pós-Graduação em Educação, UFRGS, RS.

LOURO, Guacira Lopes. Prendas e antiprendas: educando a mulher gaúcha. Educação e Realidade, Porto Alegre: UFRGS, v. 11, n. 2, p. 25-56, jul./dez. 1986.

LUIZA. Entrevista I. [Nov. 2016]. Entrevistadores: Dóris Almeida e Lucas Grimaldi. Porto Alegre, 2016.

MAGALHÃES, Justino. Contributo para a história das instituições educativas - entre a memória e o arquivo. In: FERNANDES, Rogério; MAGALHÃES, Justino. Para a história do ensino liceal em Portugal - actas dos colóquios do I centenário da reforma de Jaime Moniz(1894 - 1895). Braga: Secção de artes gráficas das oficinas de trabalho, 1999.

NOVINSKY, Anita; RIBEIRO, Eneida; GOREINSTEIN, Lina (Orgs.). Os judeus que construíram o Brasil. São Paulo: Planeta, 2015.

PERES, Eliane. A escola graduada no Rio Grande do Sul no início do século XX: a implantação de um novo modelo e de uma nova cultura escolar. In: VIDAl, Diana; SCHWARTZ, Cleonara Maria (Org.). História das Culturas Escolares no Brasil. Vitória: EDUFES, 2010.

PETRONILHA E NEUSA. Entrevista II. [Out. 2016]. Entrevistadores: Dóris Almeida e Lucas Grimaldi. Porto Alegre, 2016.

PORTELLI, Alessandro. História Oral como arte da escuta. São Paulo: Letra e voz, 2016.

POSSAMAI, Zita Rosane. Uma escola a ser vista: apontamentos sobre imagens fotográficas de Porto Alegre nas primeiras décadas do século XX. História da Educação, ASPHE, FaE, UFPel, Pelotas, v. 13, n. 29, p. 143-169, 2009.

QUADROS, Claudemir de. Reforma, ciência e profissionalização da educação: o Centro de Pesquisas e Orientação Educacionais do Rio Grande do Sul. 2006. 429 f. Tese (Doutorado em Educação) - Programa de Pós-Graduação em Educação, UFRGS, RS.

RODRIGUES, Nadir Bonini. Colégio Marista Rosário: Lições para a vida inteira (19042004). Porto Alegre: CMC, 2004. 
SANTOS, Irene (org.). Colonos e Quilombolas: memória fotográfica das colônias africanas de Porto Alegre.

SARMENTO, Manuel Jacinto. O estudo de caso etnográfico em educação. In: ZAGO, Nadir; CARVALHO, Marília Pinto de; VILELA, Rita Amélia Teixeira (orgs.). Itinerários de pesquisa: perspectivas qualitativas em sociologia da educação. Rio de Janeiro: DP\&A, 2003.

SCALABRINIANAS. História. Disponível em: 〈http://www.scalabrinianas.org.br/>. Acesso em: 19 dez. 2016.

SCHUCK, Eduardo. A qualidade de vida no trabalho dos professores da Escola Estadual de Ensino Fundamental Uruguai. 2008. 70 f. Trabalho de Conclusão de Curso ( Bacharelado em Administração) - Escola de Administração, UFRGS, RS.

SIGNOR, Lice Maria. Irmãs Missionárias de São Carlos, Scalabrinianas (1934-1971). Brasília: Csem, 2007.

SILVA, Petronilha Beatriz; PEREIRA, Neusa. Recordando nossa escola. In: FISCHER, Beatriz Daudt (Org.). Tempos de escola: memórias. São Leopoldo: Oikos, 2011.

SOUZA, Rosa Fátima. Templos da civilização: a implantação da escola primária graduada no Estado de São Paulo. São Paulo: Unesp, 1998.

SOUZA, Rosa Fátima; PINHEIRO, Antonio Carlos; LOPES, Antônio de Pádua (Orgs.). História da Escola Primária no Brasil: Investigação em perspectiva comparada em âmbito nacional. Aracaju: Edise, 2015.

VARELA, Julia. ALVAREZ-URIA, Fernando. A maquinaria escolar. Teoria \& Educação. Porto Alegre, n. 6, p. 225-246, 1992.

VIDAL, Diana Gonçalves; FARIA FILHO, Luciano Mendes. As lentes da história: estudos de história e historiografia da educação no Brasil. Campinas, SP: Autores Associados, 2005.

ZEN, Mariane Werner. Brasileiros pelas letras: atividades de associações auxiliares da escola no Grupo Escolar Alberto Torres (1941-1959), Brusque - SC. VI CONGRESSO LUSOBRASILEIRO DE HISTÓRIA DA EDUCAÇÃO: Percursos e Desafios da Pesquisa e do Ensino da História da Educação. Anais... Uberlândia, MG, 2006. 